\title{
Iron deficiency-mediated stress regulation of four subgroup Ib BHLH genes in Arabidopsis thaliana
}

\author{
Hong-Yu Wang • Marco Klatte • Marc Jakoby • \\ Helmut Bäumlein · Bernd Weisshaar · Petra Bauer
}

Received: 20 February 2007 / Accepted: 20 April 2007 / Published online: 22 May 2007

(C) Springer-Verlag 2007

\begin{abstract}
Networks of transcription factors control physiological, developmental and environmental responses. Root iron acquisition responses are controlled by the essential bHLH protein FIT. Recently, two group Ib BHLH genes were reported to be iron deficiency-regulated. Here, we studied expression patterns of these two group $\mathrm{Ib} B H L H$ genes and of their two closest homologs to analyze whether their regulation would support a function in iron deficiency responses. We found that BHLHO38, BHLHO39, BHLH1OO and $B H L H 1 O 1$ (comprising a subgroup of $B H L H \mathrm{Ib}$ genes) were up regulated by iron deficiency in roots and leaves. Single insertion mutants had no visible phenotype and were capable of inducing root iron acquisition responses, presumably due to functional redundancy. Specific metal treatments like nickel, high zinc or high copper resulted in
\end{abstract}

H.-Y. Wang and M. Klatte contributed equally to this work.

Electronic supplementary material The online version of this article (doi:10.1007/s00425-007-0535-x) contains supplementary material, which is available to authorized users.

H.-Y. Wang $\cdot$ M. Klatte $\cdot$ P. Bauer $(\square)$

Department of Biosciences, Botany, Saarland University,

PO Box 151150, 66041 Saarbrücken, Germany

e-mail: p.bauer@mx.uni-saarland.de

M. Jakoby $\cdot$ B. Weisshaar

Max-Planck Institute for Plant Breeding Research,

Carl-von Linné-Weg 10, 50829 Köln, Germany

\section{H. Bäumlein}

Institute of Plant Genetics and Crop Plant Research (IPK),

Corrensstr. 3, 06466 Gatersleben, Germany

B. Weisshaar

Faculty of Biology, University of Bielefeld,

33594 Bielefeld, Germany induction of the four $B H L H$ Ib genes whereas high iron, low copper and low zinc repressed gene expression. Induction of the four $B H L H \mathrm{Ib}$ genes was also found in multiple iron acquisition mutants including fit. Ectopic activation of FIT did not suppress the four BHLH Ib genes. Split-root analyses using promoter-GUS lines showed that FIT and BHLH1OO promoters were controlled by different local and systemic signals involved in their regulation by iron. These results indicated that the four $B H L H \mathrm{Ib}$ genes were induced independently from $F I T$ by conditions causing iron deficiency. Taken together, BHLH038, BHLH039, BHLH1OO and BHLH1O1 function differently from FIT and may be involved in mediating a signal related to iron deficiencyinduced stress and/or internal iron homeostasis.

Keywords bHLH - Basic helix-loop-helix · Fer-like iron-deficiency induced transcription factor (FIT) . Iron acquisition $\cdot$ Iron uptake $\cdot$ Split root .

Transcription factor

Abbreviations
$\begin{array}{ll}\text { bHLH } & \text { Basic helix-loop-helix } \\ \text { FIT } & \begin{array}{l}\text { Fer-like iron-deficiency induced } \\ \text { transcription factor }\end{array} \\ \text { FIT1 } & \text { Fe-deficiency induced transcription factor } \\ \text { MU } & \text { 4-Methylumbeliferyl- } \beta \text {-D-glucuronide } \\ \text { qRT-PCR } & \text { Quantitative reverse transcription PCR }\end{array}$

\section{Introduction}

Iron is a crucial metal element required for many vital metabolic processes in plants. Although abundant in soil, iron is mainly present in its oxidized form Fe (III) that has a low solubility. Especially on alkaline and calcareous soils 
concentrations of bio-available iron are usually too low to meet plants requirements. To overcome this shortage plants have evolved different strategies to mobilize iron from the soil (Römheld 1987). Dicot plants such as Arabidopsis acidify the soil, reduce iron via the membrane-bound iron reductase FRO2 and subsequently take up Fe (II) through the membrane-bound divalent metal transporter IRT1. This iron mobilization system is strictly regulated. At low iron supply FRO2 and IRTI genes are induced whereas upon sufficient iron supply the genes are down regulated (Eide et al. 1996; Robinson et al. 1999; Vert et al. 2002). A central transcriptional regulator in this process in tomato is the basic helix-loop-helix (bHLH) factor FER; the A. thaliana ortholog is encoded by the gene FIT (= fer-like iron deficiency-induced transcription factor, previously known as FRU and FIT1, gene number At2 g28160; Bauer et al. 2004; Colangelo and Guerinot 2004; Jakoby et al. 2004; Yuan et al. 2005; FIT was renamed by Bauer, Guerinot and Ling). FER and FIT share higher sequence similarity with each other rather than with any other known bHLH protein from the two species. FER is required for induction of iron reductase and iron transporter genes in tomato (Ling et al. 2002; Bereczky et al. 2003; Bauer et al. 2004; Li et al. 2004). FIT was found essential for the induction of FRO2 upon iron deficiency in Arabidopsis (Colangelo and Guerinot 2004; Jakoby et al. 2004) as well as for induction of IRT1 (Jakoby et al. 2004). In our previous studies we utilised two loss of function fit alleles that were not capable of producing any functional FIT protein. One allele has a T-DNA insertion in an exon (fit-3 $=$ fru-G108), the other allele contains a premature EMS-induced stop codon in an exon (Jakoby et al. 2004). Loss of function of FER and FIT resulted in lethal leaf chlorosis due to insufficient iron uptake in tomato and in Arabidopsis (Ling et al. 2002; Colangelo and Guerinot 2004; Jakoby et al. 2004). Expression of FER and FIT was induced by low iron supply compared to sufficient and/or generous iron supply suggesting that iron mobilization is controlled by a cascade of transcription factors with FER/FIT genes being part of it. Interestingly, several examples of plant $B H L H$ genes have been found to act within networks of $B H L H$ transcription factor genes, such as in phytochrome signaling (reviewed by Duek and Fankhauser 2005) and epidermal cell patterning (reviewed by Schiefelbein 2003; more examples found in Heim et al. 2003; Toledo-Ortiz et al. 2003). Therefore, it is likely that the protein FIT also acts in a network of transcription factors, perhaps even a network of bHLH transcription factors. The identification of transcription factors in Arabidopsis is eased by the availability of the complete genome sequence and functional genome projects. In a recent study Vorwieger et al. (2007) identified two iron-regulated BHLH genes whose function in Arabidopsis was however, not investigated any further by these authors. Here, we studied regulation of these two BHLH genes (BHLH038, BHLHO39) and of their closest homologs (BHLH1OO, BHLH1O1) that we termed subgroup $\mathrm{Ib} B H L H$ genes in leaves and roots in various nutritional situations as well as in mutant backgrounds and split-root situations related to iron deficiency.

\section{Materials and methods}

Plant material and growth condition

Arabidopsis thaliana seeds were from wild type ecotype Col-0 and the mutant GABI-Kat fit-3 = formerly fru-G108 T-DNA insertion line (further description in Jakoby et al. 2004). Seeds of homozygous fit-3 mutant plants could be obtained after germination on high iron Hoagland medium under low light conditions and continuous spraying with iron fertilizer sequestrene after transfer into soil. $p 35 S:: F I T$ overexpression plants were previously described (Ox 1 and 7 lines, Jakoby et al. 2004). frdl-1 and manl seeds were obtained from the stock center. irtl-1 seeds were kindly provided by Dr. C. Curie (Montpellier).

T-DNA insertion mutants for $B H L H$ genes were obtained from the stock center (bhlh038-1=SALK_020183, bhlh039-1 = SALK_025676, bhlh100-1 = SALK_074568, bhlh101-1 = SALK_011245). Homozygous insertion plants were selected by genomic PCR according to the procedure described at http://www.signal.salk.edu/.

For iron deficiency experiments, seeds were surfacesterilized and vertically germinated on agar plates containing Hoagland medium (Jakoby et al. 2004). Ten or 14 dayold seedlings were transferred to Hoagland medium lacking FeEDTA and supplied with $50 \mu \mathrm{M}$ ferrozine $(-\mathrm{Fe})$ or to Hoagland medium containing $50 \mu \mathrm{M}$ FeEDTA $(+\mathrm{Fe})$, respectively, for 3 or 5 days, as indicated in the text. Culture conditions were set to $21^{\circ} \mathrm{C}$ and long days $(16 \mathrm{~h} \mathrm{light}$ and $8 \mathrm{~h}$ dark). Metal treatments were performed by transferring 14-day-old seedlings for 5 days to Hoagland medium with indicated changes of the metal concentrations. As a control served regular Hoagland medium containing $50 \mu \mathrm{M}$ iron, $2 \mu \mathrm{M}$ zinc, $1.5 \mu \mathrm{M}$ copper, 0 nickel. Metal treatments were performed by changing individual metal-salt concentrations in the Hoagland medium to $500 \mu \mathrm{M} \mathrm{Fe}$ (high iron), $0 \mathrm{Fe}$ (no iron), $100 \mu \mathrm{M} \mathrm{Zn} \mathrm{(high}$ zinc), $0 \mathrm{Zn}$ (no zinc), $32 \mu \mathrm{M} \mathrm{Cu}$ (high copper) or $0 \mathrm{Cu}$ (no copper) or by adding $60 \mu \mathrm{M} \mathrm{NiCl}_{2}$, respectively.

Promoter- $\beta$-glucuronidase (GUS) transgenic lines were constructed as follows: $1,260 \mathrm{bp}$ promoter upstream of the ATG start codon of $B H L H 038$ and 1,240 bp promoter upstream of the ATG start codon of BHLHO39 were amplified and cloned into pTOPO-ENTR vector (Invitrogen, Carlsbad, CA, USA) and sequenced. Error-free inserts were recombined into pBLUE, a GATEWAY compatible binary 
promoter-GUS fusion vector based on pPAM (GenBank AY027531). 1,173 bp promoter upstream of the ATG start codon of $B H L H 100$ and 1,172 bp promoter upstream of the ATG start codon of BHLH1O1 were amplified and cloned into pCR4-TOPO-TA (Invitrogen) and sequenced. Errorfree inserts were cloned into pATGUS vector, a binary promoter-GUS fusion vector based on pPAM and pBT-GUS. Transgenic lines were generated by Agrobacterium tumefaciens-mediated transformation of Arabidopsis plants (Col-0) according to the floral dip protocol (Clough and Bent 1998) and selected on kanamycine (pBHLH038-GUS and $\mathrm{p}$ BHLH039-GUS) or Basta ( $\mathrm{p}$ BHLH100-GUS and $\mathrm{p}$ BHLH101-GUS) selection medium and self-fertilised. Ten lines per construct were tested. Selected lines were multiplied and further analyzed in the T2 generation.

For split-root assays 2-week-old plants germinated on $100 \mu \mathrm{M}$ Fe-containing Hoagland medium were root-capitated $2 \mathrm{~cm}$ below the hypocotyl. Two weeks later plants were transferred to three-chambered Petri dishes with lateral roots bent to either side of two chambers filled with 0 $\mathrm{Fe} / 50 \mu \mathrm{M}$ ferrozine and $100 \mu \mathrm{M} \mathrm{Fe}$, respectively. Plants were analyzed three days later.

\section{Analysis of GUS activity}

For histochemical GUS staining Arabidopsis plants were washed in sodium phosphate buffer (pH 7.0) and incubated in GUS staining buffer $(50 \mathrm{mM}$ sodium phosphate, $2 \mathrm{mM}$ potassium ferrocyanide, $2 \mathrm{mM}$ potassium ferricyanide, 0.2 $\%$ Triton X-100, 2 mM GUS substrate 5-bromo-4-chloro3-indolyl-beta-d-glucuronic acid) at $37^{\circ} \mathrm{C}$ for $8 \mathrm{~h}$ (Jefferson et al. 1987). Then the plants were incubated in $100 \%$ ethanol for de-staining, and kept in 70\% ethanol before observation. Ten micro meter sections were obtained after embedding into paraplast as described in Bereczky et al. (2003). Fluorimetric GUS activity tests were performed on protein extracts using $2 \mathrm{mM} 4$-methylumbeliferyl- $\beta$-D-glucuronide as substrate as described by Jakoby et al. (2004).

\section{Gene-expression analysis}

Expression was analysed by quantitative real-time reverse transcription-PCR. Total RNA was prepared from leaf and root material using the Invisorb Spin Plant RNA Mini Kit (Invitek, Berlin, Germany). Total RNA $(0.5-1 \mu \mathrm{g})$ was DNase-treated (Fermentas, Vilnius, Lithuania) and used for cDNA synthesis. cDNA was synthesized using oligo-dT primers (RevertAid first strand cDNA synthesis kit, Fermentas). $10 \mu \mathrm{l}$ of $1: 100 \mathrm{cDNA}$ dilution was pipetted to $10 \mu \mathrm{l}$ PCR mastermix so that pipetting errors were minimized. According to database and experimental analysis two housekeeping genes from independent physiological pathways were chosen as constitutive controls (EF1BAL-
PHA2, UBP6). Specific PCR oligonucleotides (Table 1) were designed using the Primer3 software (Rozen and Skaletzky 2000), and the primer specificity was checked by BLASTN search against the Arabidopsis genome and EST databases. The primers were designed to span an intron wherever possible. Additionally, for EF1BALPHA2 we designed primer pairs amplifying only genomic DNA, allowing us to substract genomic DNA contamination if necessary. Amplification was performed using TaKaRa Ex Taq R-PCR version 2.1 in combination with SYBR Green I (Roche Diagnostics, Mannheim, Germany) on a Mx3000P PCR cycler (Stratagene, La Jolla, CA, USA). To quantify gene expression levels and to determine PCR efficiency, serial dilutions of standards (1 kb PCR fragments amplified from cDNA or BAC clones) were amplified in parallel as template in each PCR run. Each sample was amplified in duplicate technical repetitions. The deviations of the threshold cycles between the technical repetitions were very low. Medium or high abundant transcripts were amplified with CT variations below 0.2 (= $1 \mathrm{CT}$, corresponding to one duplication cycle). Even for very low transcript abundances (100 or less transcripts per reaction) the variation in threshold cycles between the duplicates was maximally $1 \mathrm{CT}$. The quality of each PCR reaction was verified by meltcurve analysis and in part by agarose gel electrophoresis.

Data analysis was performed by using the MxPro QPCR software (version 3.00). All samples were checked for correct individual amplification profiles, then averages of the technical repetitions were utilised. Samples were normalized using the averaged expression values of the controls EF1BALPHA2 and UBP6. These normalized absolute expression values were represented in diagrams in logarithmic scale. Due to the very low variations between the technical duplicates standard deviations were not apparent in the $\log$ scale and are not indicated in the diagrams. Each experiment has been confirmed in 2-5 independent biological repetitions.

\section{Results}

Expression of BHLHO38, BHLHO39, BHLH1OO and $B H L H 101$ genes in response to iron supply

Previous studies had indicated that BHLHO38 and BHLH039 were regulated by iron supply in whole seedlings. Their close homologs BHLH1OO and BHLH1O1 had not been studied yet. To determine in more detail in which organs these four $B H L H$ genes (subgroup $\mathrm{Ib} B H L H$ genes $=$ BHLHO38, BHLHO39, BHLH1OO and BHLH1O1) are expressed, we analysed mRNA levels in leaves and roots of plants grown upon sufficient and low iron supply by quantitative real-time RT-PCR (five repetitions with all 
Table 1 Genes and gene specific primers used for real-time qRT-PCR analysis

\begin{tabular}{ll}
\hline Sequences of oligonucleotide primers & Gene (AGI code) \\
\hline F 5'-GGAGAAGGTGTTGCTCCATC-3' & FIT (At2 g28160) \\
R 5'-TCCGGAGAAGGAGAGCTTAG-3' & BHLH038 (At3 g56970) \\
F 5'-AGCAGCAACCAAAGGCG-3' & \\
R 5'-CCACTTGAAGATGCAAAGTGTAG-3' & BHLH039 (At3 g56980) \\
F 5'-GACGGTTTCTCGAAGCTTG-3' & \\
R 5'-GGTGGCTGCTTAACGTAACAT-3' & BHLH100 (At2 g41240) \\
F 5'-AAGTCAGAGGAAGGGGTTACA-3' & \\
R 5'-GATGCATAGAGTAAAAGAGTCGCT-3' & BHLH101 (At5 g04150) \\
F 5'-CAGCTGAGAAACAAAGCAATG-3' & \\
R 5'-CAGTCTCACTTTGCAATCTCC-3' & IRT1 (At4 g19690) \\
F 5'-AAGCTTTGATCACGGTTGG-3' & \\
R 5'-TTAGGTCCCATGAACTCCG-3' & FRO2 (At1 g01580) \\
F 5'-CTTGGTCATCTCCGTGAGC-3' & \\
R 5'-AAGATGTTGGAGATGGACGG-3' & EF1Balpha2 (At5g19510) cDNA \\
F 5'-ACTTGTACCAGTTGGTTATGGG-3' & \\
R 5'-CTGGATGTACTCGTTGTTAGGC-3' & EF1Balpha2 (At5 g19510) genomic DNA \\
F 5'-TCCGAACAATACCAGAACTACG-3' & \\
R 5'-CCGGGACATATGGAGGTAAG-3' & UBP6 (At1 g51710) \\
F 5'-GAAAGTGGATTACCCGCTG-3' & \\
R 5'-CTCTAAGTTTCTGGCGAGGAG-3' & \\
\hline
\end{tabular}

Fig. 1 a, b Expression analysis of BHLH038, BHLH039, BHLH1OO and BHLH1O1 in response to iron deficiency $(-\mathrm{Fe})$ and normal iron supply $(+\mathrm{Fe})$ in roots and leaves of wild type plants (a) and two FIT overexpression lines (Ox1 and $\mathrm{Ox} 7, \mathbf{b})$. Expression was analyzed by quantitative real-time reverse transcription-PCR. Absolute expression levels were normalized against constitutive controls as described in "Materials and methods"

$B H L H$ genes, eight repetitions with $B H L H 100$ ). BHLH038, BHLH039, BHLH1OO and BHLH1O1 transcripts were present at lower level in iron-sufficient wild type roots and leaves compared to iron deficient conditions (Fig. 1a). Analysis of different experiments showed that relative induction levels of $B H L H$ genes $(-\mathrm{Fe}$ vs. $+\mathrm{Fe})$ varied in our growth conditions between 10 and 100 times in roots (Figs. 1a, 2, 4, 6). FIT was found induced by a factor of
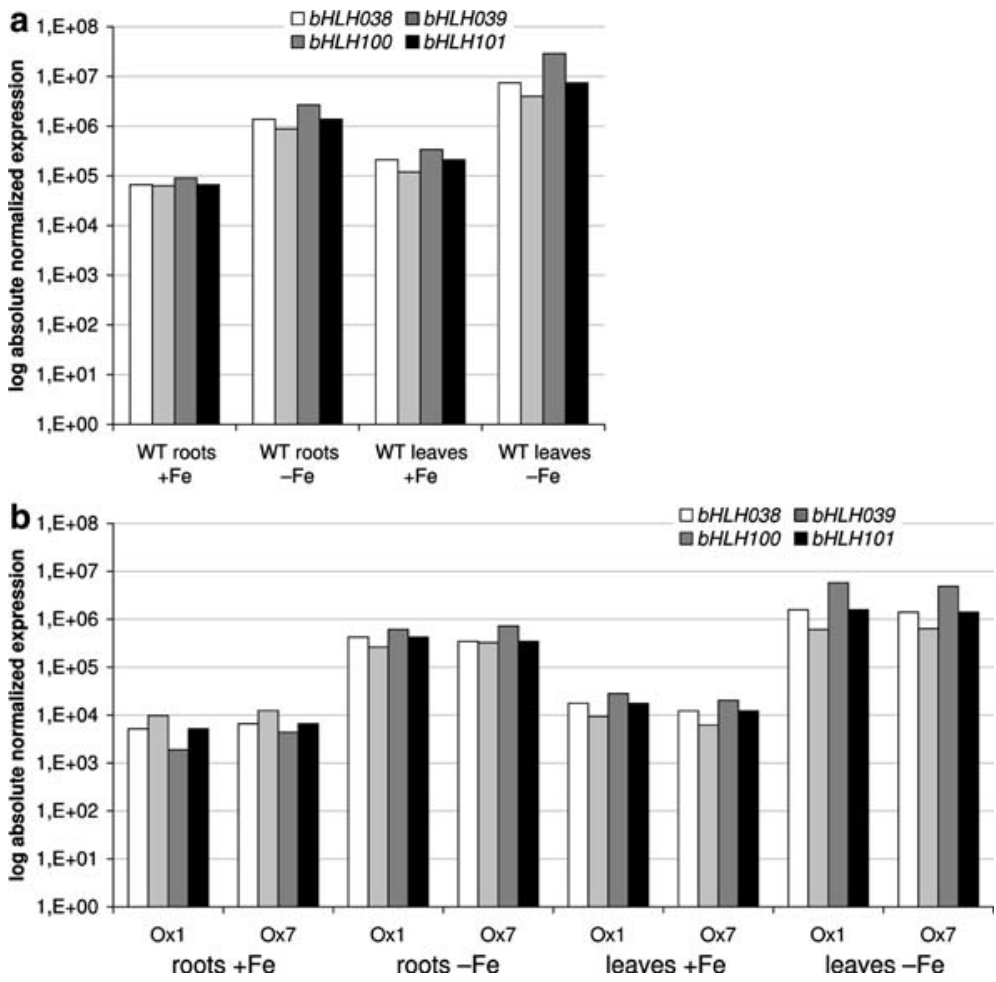

about 3-4 maximally whereas $F R O 2$ and IRTI were induced by a factor of about 10-50 times in our growth conditions (data not shown, compare to Jakoby et al. 2004). The four $B H L H$ genes were also induced in leaves upon iron deficiency treatment in contrast to FIT, FRO2 and IRT1 (Fig. 1a). This indicated that the four BHLH genes might have a function in iron deficiency responses in leaf and in root tissues. 
Fig. 2 a, b Time course experiment of IRT1, FRO2, FIT (a)

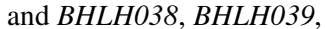
BHLH1OO and BHLH1OI (b) expression in response to iron deficiency in roots of wild type plants. Two week-old wild type plants were transferred from $10 \mu \mathrm{M}$ Fe Hoagland medium to $0 \mu \mathrm{M}$ Fe plus ferrozine. Roots samples were collected $0,12,24$, $36,48,72,120 \mathrm{~h}$ after transfer to iron deficient medium. Expression was analyzed by quantitative real-time reverse transcription-PCR. Absolute expression levels were normalized against constitutive controls as described in "Materials and methods"
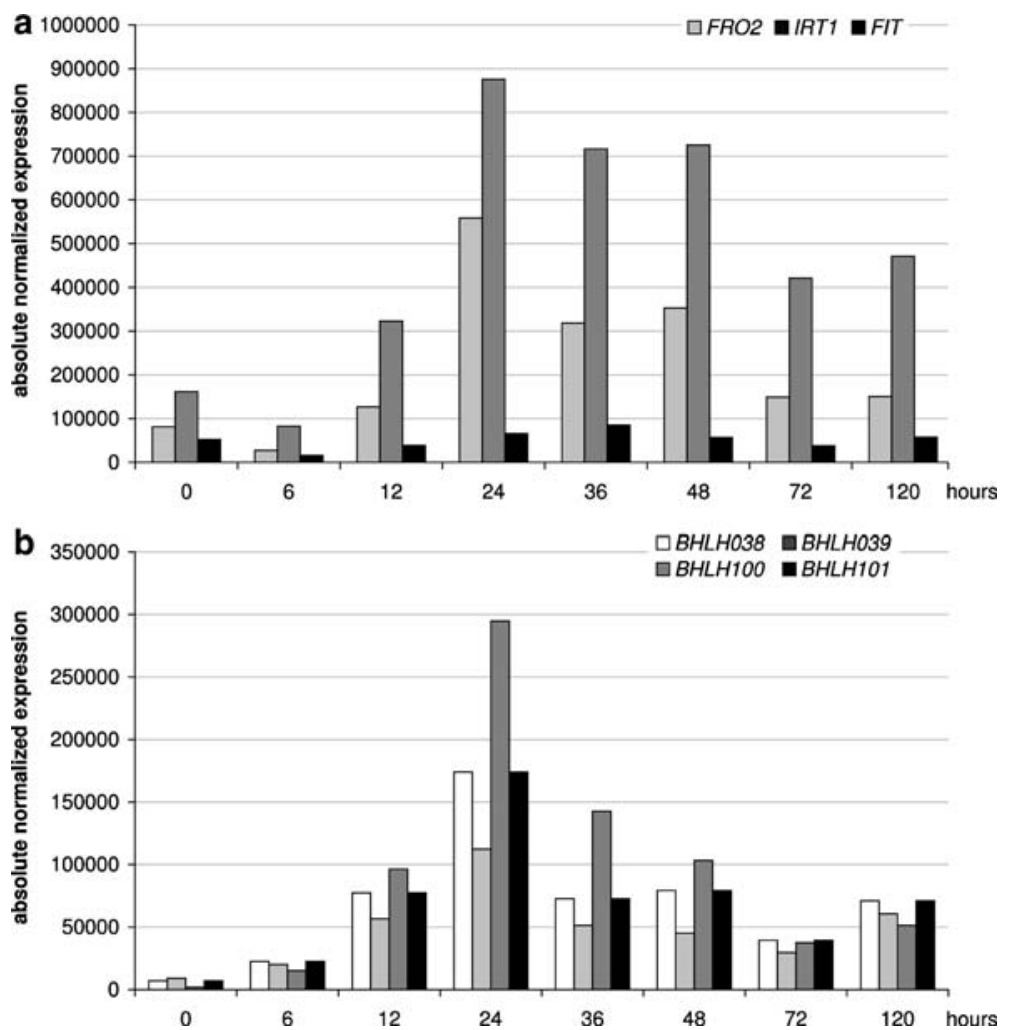

Time course experiments showed that by $24 \mathrm{~h}$ after transfer of the plants to iron deficiency conditions all four BHLH genes were maximally up regulated in roots compared to the control situation (Fig. 2). A similar situation was found for FIT, FRO2 and IRT1 although the decrease in expression levels were lower after the 24-h time point than for the $B H L H$ genes.

Thus, reverse transcription-PCR expression results showed that BHLH038, BHLHO39, BHLH1OO and $B H L H 101$ were regulated in a similar manner by iron.

\section{bhlh038-1, bhlh039-1, bhlh100-1 and bhlh101-1 T-DNA} exon insertion mutants did not show apparent phenotypes

To further obtain functional hints about the four $B H L H$ genes, we selected homozygous T-DNA exon insertion lines for all four genes and performed an iron deficiency response experiment with them (two repetitions). This experiment consisted in exposing the plants to $+\mathrm{Fe}(50 \mu \mathrm{M}$ $\mathrm{Fe})$ or $-\mathrm{Fe}(0 \mathrm{Fe}, 50 \mu \mathrm{M}$ ferrozine $)$ for 3 days and measuring gene expression of IRT1, FRO2 and FIT. In none of the lines we were able to detect any leaf chlorosis symptoms and reduced growth (data not shown). All four bhlh mutants were able to induce FIT, IRT1 and FRO2 induction (Fig. 3, shown for bhlh039-1 and bhlh100-1). We further analyzed $B H L H$ gene induction by low iron in the bhlh ko lines using real time qRT-PCR (Suppl. Fig. 1). The real time PCR primers recognized in all four cases sites downstream of the T-DNA insertion. In bhlh038 ko, bhlh039 ko and bhlh100 ko lines the T-DNA was inserted with the left border flanking the $3^{\prime}$ end of the coding sequence. In these three lines the respective mutated transcripts were significantly down regulated or absent. In the bhlh101 ko line, the T-DNA was oriented in the opposite direction and transcripts were found to almost the same level as in wild type. In all four cases, all other $B H L H$ genes were still induced to the same level as seen in wild type. Significant trans-effects of T-DNA insertion alleles on gene expression of other $B H L H$ genes were not noted. Therefore, one possible explanation for these observations was that the subgroup Ib $B H L H$ genes had redundant gene functions.

\section{BHLH038, BHLH039, BHLH1OO and BHLH1O1 gene}

expression in different metal supply conditions

To get further hints on $B H L H$ gene function despite of their potential redundancy, we analyzed subgroup $\mathrm{Ib} B H L H$ gene expression under various growth conditions. First, we studied whether expression of the four subgroup Ib $B H L H$ genes was affected by different metal supply conditions (two repetitions). We exposed wild type plants for 5 days to $500 \mu \mathrm{M}$ Fe (high iron) or to $-\mathrm{Fe}$ (no iron). In addition, we exposed plants to $100 \mu \mathrm{M} \mathrm{Zn}$ (high zinc), $-\mathrm{Zn}$ (no zinc), $32 \mu \mathrm{M} \mathrm{Cu}$ (high copper), $-\mathrm{Cu}$ (no copper) and $60 \mu \mathrm{M} \mathrm{Ni}$ (nickel) supply, respectively. Control plants were exposed to regular Hoagland medium containing $50 \mu \mathrm{M} F e, 2 \mu \mathrm{M}$ 


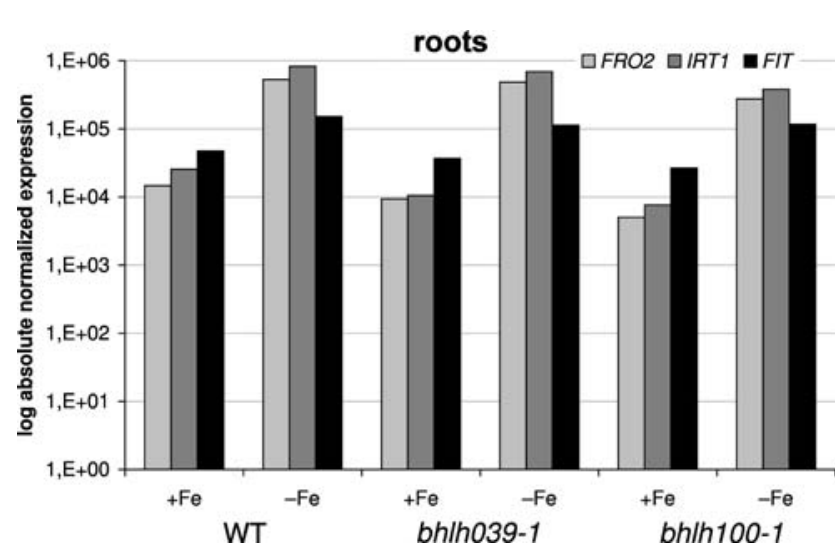

Fig. 3 Analysis of single T-DNA insertion lines bhlh039-1 and bhlh100-1. Ten day-old homozygous insertion plants were transferred for three days to iron deficiency conditions $(0 \mathrm{Fe}, 50 \mu \mathrm{M}$ ferrozine $)$ versus the control ( $50 \mu \mathrm{M} \mathrm{Fe})$. Expression of IRT1, FRO2 and FIT was analyzed in roots by quantitative real-time reverse transcription-PCR. Absolute expression levels were normalized against constitutive controls as described in "Materials and methods"

$\mathrm{Zn}, 1.5 \mu \mathrm{M} \mathrm{Cu},-\mathrm{Ni}$. The above metal supply conditions have been previously determined by us to result in moderate stress symptoms after the first week of application (for example leaf chlorosis, but no immediate death). We found that expression of all four subgroup Ib $B H L H$ genes was enhanced in roots and leaves when plants were grown upon $-\mathrm{Fe}, 100 \mu \mathrm{M} \mathrm{Zn}$, and $60 \mu \mathrm{M} \mathrm{Ni}$ compared to the control
(Fig. 4). In roots expression was also up regulated in response to $32 \mu \mathrm{M} \mathrm{Cu}$, whereas in the same plants expression was decreased in leaves in response to $32 \mu \mathrm{M} \mathrm{Cu}$ compared to the control (Fig. 4). We observed that in leaves, $500 \mu \mathrm{M} \mathrm{Fe},-\mathrm{Zn}$ and $-\mathrm{Cu}$ conditions caused a dramatic decrease in expression of all subgroup $\mathrm{Ib} B H L H$ genes. In roots, $500 \mu \mathrm{M} \mathrm{Fe},-\mathrm{Zn}$ and $-\mathrm{Cu}$ had no clear effect on subgroup Ib $B H L H$ gene expression. It was remarkable for us to note that despite of the visible leaf stress symptoms caused by iron excess (namely whitish leaf margins) subgroup $\mathrm{Ib} B H L H$ genes were not induced but rather repressed. This observation indicated to us that subgroup $\mathrm{Ib}$ $B H L H$ genes were not generally stress-regulated but regulated only by particular stress situations.

In comparison, FIT was maximally induced up to three times in roots under the conditions $-\mathrm{Fe}, 100 \mu \mathrm{M} \mathrm{Zn}$ and $32 \mu \mathrm{M} \mathrm{Cu}$ (data not shown). This induction was likely the consequence of iron deficiency caused by metal excess. In agreement with this, we found that $F R O 2$ was also induced by $-\mathrm{Fe}, 100 \mu \mathrm{M} \mathrm{Zn}, 32 \mu \mathrm{M} \mathrm{Cu}$ and $60 \mu \mathrm{M} \mathrm{Ni}$ (Fig. 4). From these experiments we concluded that subgroup $\mathrm{Ib}$ $B H L H$ genes were regulated by metal supply. Most likely high zinc, high copper and nickel resulted in internal iron deficiency, so that we deduced that subgroup Ib $B H L H$ genes were regulated mainly by internally sensed iron deficiency. We also noted that the four BHLH genes showed similar gene expression profiles in the various nutritional
Fig. 4 a, b Expression analysis of FRO2, BHLHO38, BHLHO39, $B H L H 1 O O$ and BHLH1O1 in response to different metal supply conditions in roots (a) and leaves (b) of wild type plants. Fourteen day-old seedlings were transferred for five days to solid agar medium with the respective metal supply and metal deficiency conditions. Expression was analyzed by quantitative real-time reverse transcription-PCR. Absolute expression levels were normalized against constitutive controls as described in Materials and methods. Asterisks indicate that expression was zero, whereas $E F 1 B$ and $U B P$ control genes were expressed normally
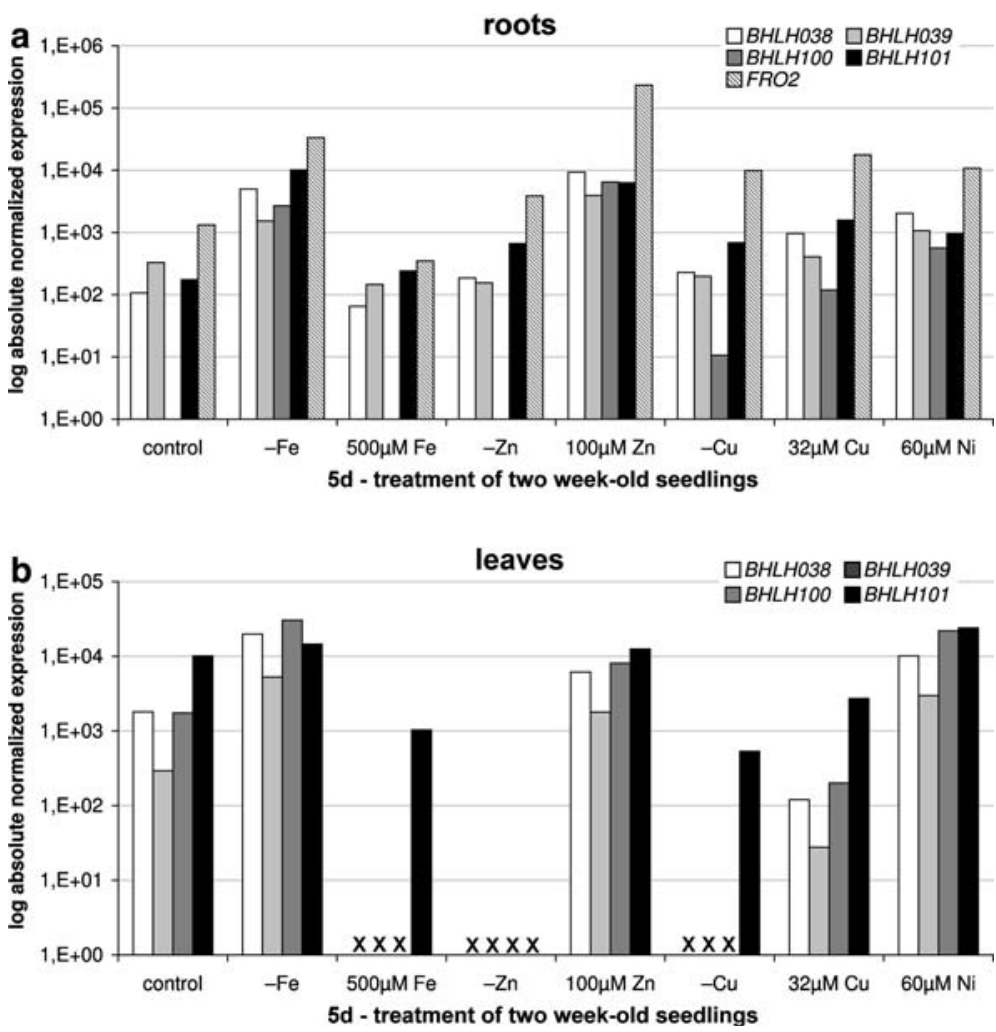
situations, which suggested again a common regulatory pathway and supported genetic redundancy of the four genes.

\section{BHLH038, BHLHO39, BHLH1OO and BHLH1O1 gene} expression in iron mobilization mutants

To analyze whether subgroup Ib $B H L H$ gene induction was related to local iron deficiency or to iron deficiency sensed internally by the plant we performed studies of subgroup $\mathrm{Ib}$ $B H L H$ gene expression in the background of various iron mobilization mutants (two repetitions with all $B H L H$ genes, three repetitions with $B H L H 100$ ). These mutants were chlorotic due to their inefficient capacity of acquiring or utilising iron.

In the first place we characterized the fit-3 allele further. The fit-3 allele harbours a T-DNA insertion in an exon so that functional mRNA and protein cannot be produced. fit-3 mutant plants were chlorotic when they were germinated and grown on Hoagland medium containing $50 \mu \mathrm{M}$ Fe or less as shown previously (Jakoby et al. 2004). When grown on $50 \mu \mathrm{M}$ Fe medium fit-3 plants displayed similar leaf chlorosis symptoms as wild type plants grown on $0 \mu \mathrm{M} \mathrm{Fe}$ in the same assay conditions. At $0 \mu \mathrm{M}$ Fe fit-3 mutants were very severely growth-retarded. fit-3 mutants could be rescued when they were grown on $200 \mu \mathrm{M}$ Fe Hoagland medium (data not shown). fit-3 mutants did not induce $F R O 2$ and IRT1 in roots to the same levels as wild type plants upon iron deficiency as shown previously by Jakoby et al. (2004). Here, we analyzed auto-regulation of the FIT promoter in the fit-3 background. For these experiments we crossed a promoter $p F I T$-GUS line with the fit-3 mutant and compared GUS activity patterns conferred by the same GUS transgene insertion in the homozygous fit-3 background with that in the wild type background. Histochemical GUS staining together with statistically analysed kinetic enzyme assays showed that FIT promoter activity was decreased in the fit-3 mutant background upon iron deficiency compared to wild type (Fig. 5). Upon sufficient iron supply, the GUS patterns were comparable between the two genetic backgrounds. Hence, the FIT gene was required for its own promoter induction upon iron deficiency as indicated previously (Jakoby et al. 2004).

Next, we analyzed the molecular-genetic interaction between the iron uptake regulator gene FIT and the four iron-regulated $B H L H$ genes. To study whether the four $B H L H$ genes were dependent on FIT or not, we studied expression of the four subgroup $\mathrm{Ib} B H L H$ genes in the fit-3 mutant background. We found that BHLHO38, BHLHO39, BHLH1OO and BHLH1O1 transcripts were expressed at higher level in roots and leaves of fit-3 plants compared to similarly grown wild type plants (Fig. 6). This was in contrast to IRTI and FRO2, which were significantly down

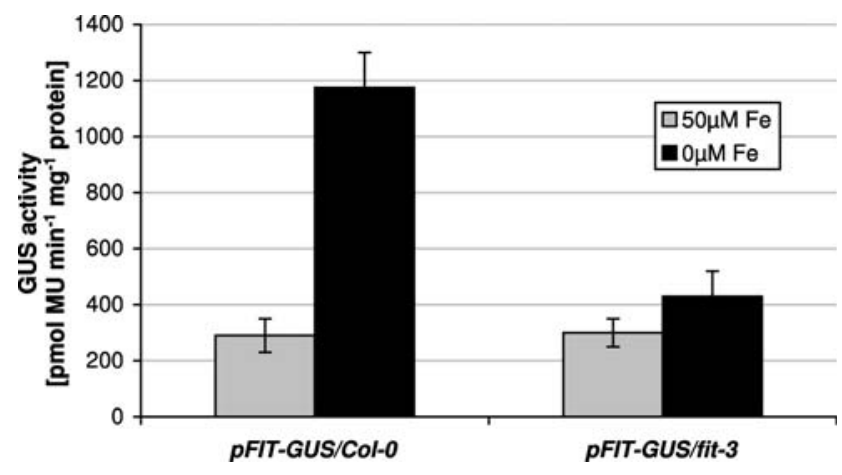

Fig. 5 Fluorimetric analysis of pFIT-GUS activity in protein extracts of plants with wild type and fit-3 mutant background. Mean values $\pm \mathrm{SD}$ were determined for four measurements, whereby each measurement included 5-8 plant samples

regulated in the fit-3 mutant (Jakoby et al. 2004). Therefore, FIT was not required for iron deficiency-mediated induction of the four $B H L H$ genes but it was required for induction of its own FIT promoter and for induction of $F R O 2$ and IRTI.

To test whether other iron mobilization mutants with chlorotic phenotypes were capable of expressing and upregulating subgroup $\mathrm{Ib} B H L H$ genes, we compared gene expression in $f r d l-1$ mutant plants (FRO2 mutant, devoid of iron reductase activity; Robinson et al. 1999), irt1-1 mutant plants (devoid of iron transporter activity; Vert et al. 2002), and manl mutant plants (also known as frd3-3, improper iron transport to the shoot; Rogers et al. 2002). Generally, these mutant plants were more chlorotic than wild type plants upon iron deficiency. In our assay condition, irt $1-1$ mutants appeared as most chlorotic among the mutants analyzed here. Interestingly, we found that the four BHLH genes were induced in the roots of iron mobilization mutants to a higher degree than in wild type plants grown under the same conditions (Fig. 6). In all mutants analyzed subgroup Ib $B H L H$ gene expression was higher upon iron deficiency than upon sufficient iron supply. In leaves, subgroup Ib $B H L H$ gene expression gave a similar expression than in roots with higher induction by iron deficiency compared to iron supply, and higher expression in mutants compared to wild type. The most chlorotic mutant irtl-1 had highest expression levels of BHLH genes. frdl-1 mutants did not appear chlorotic in iron supply conditions in our assay. This result indicated that subgroup Ib $B H L H$ gene expression was likely correlated with the internal iron nutritional status in the plants. We could also note again that the four $B H L H$ genes showed very similar gene induction characteristics suggesting a common regulatory pathway and gene redundancy.

As a control, we studied expression of $F I T$ in roots of frdl-1, irtl-1 and manl plants. Expression of FIT was induced to about three to eightfold in the mutants compared 
Fig. 6 a, b Expression analysis of BHLHO38, BHLHO39, BHLH1OO and BHLH1O1 in roots (a) and leaves (b) of iron mobilization mutants. Ten dayold seedlings of the various genotypes were transferred for 3 days to $50 \mu \mathrm{M}$ iron supply or iron deficiency $(0 \mathrm{Fe}, 50 \mu \mathrm{M}$ ferrozine). Expression was analyzed by quantitative real-time reverse transcription-PCR.

Absolute expression levels were normalized against constitutive controls as described in

"Materials and methods"
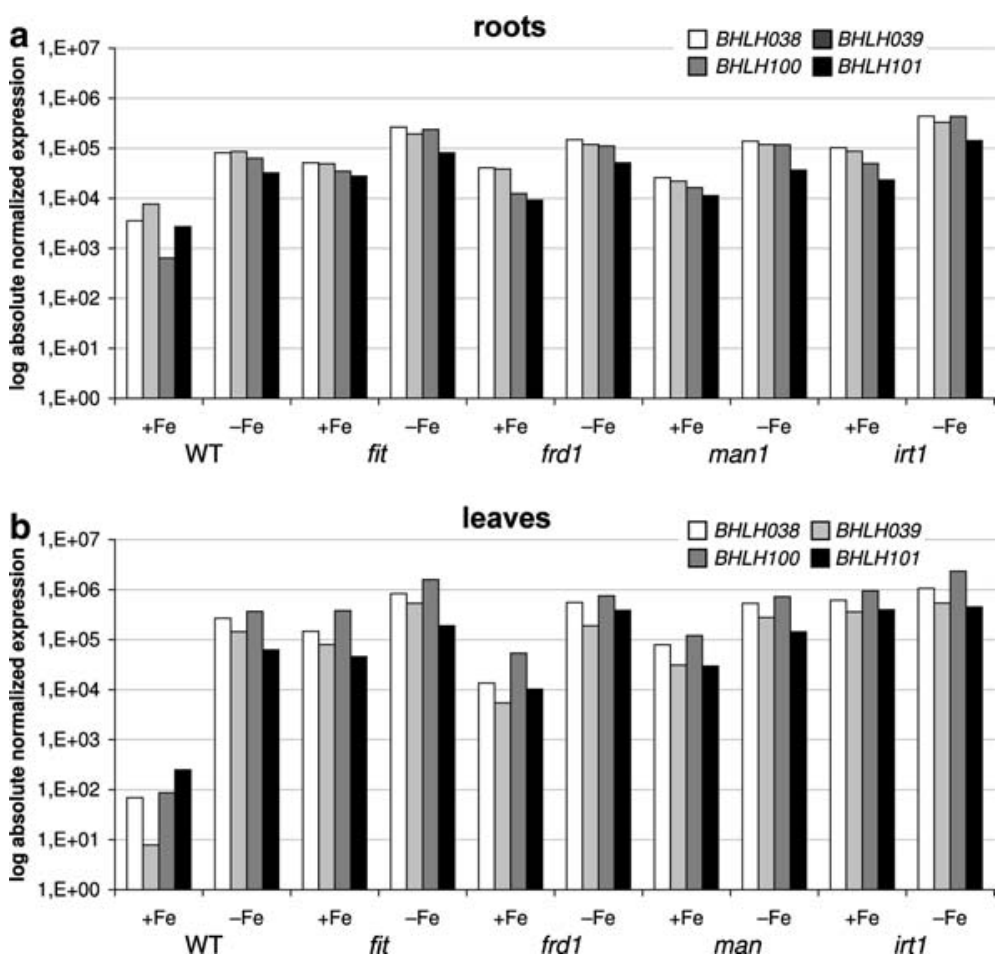

to the control indicating that indeed the mutants experienced iron deficiency (data not shown).

Although it seemed unlikely from the just described experiments we verified that $F I T$ was not a negative regulator of $B H L H$ genes. Therefore, we analysed gene expression of the four $B H L H$ genes in two transgenic lines that overexpressed $F I T$ via the cauliflower mosaic virus $35 \mathrm{~S}$ promoter (Ox1 and Ox7 lines, Jakoby et al. 2004). These Ox plants expressed $F R O 2$ and $I R T 1$ ectopically in leaves when the plants were exposed to iron deficiency indicating that the overexpression transgene was functional upon iron deficiency in leaves (Jakoby et al. 2004). On the other hand, the FIT overexpression plants did not show increased $F R O 2$ and IRTI expression upon iron supply in leaves (Jakoby et al. 2004) suggesting that FIT overexpression might be inactive upon iron supply. We analysed whether ectopic FIT expression would affect regulation of the four $B H L H$ genes. All four subgroup $\mathrm{Ib} B H L H$ genes were found induced in leaves and roots of FIT overexpression plants that had been exposed to iron deficiency compared to iron supply (Fig. 1b). Therefore, FIT was not required to suppress subgroup Ib $B H L H$ gene expression when it was active. In roots and leaves of iron sufficient FIT overexpression plants subgroup $\mathrm{Ib} B H L H$ genes were also expressed, however, their expression levels were decreased relative to wild type (Fig. 1b). This latter observation reflected perhaps the better iron mobilization capacity of FIT overexpression plants.

From these experiments we concluded that FIT was also not required for down-regulation of the subgroup $\mathrm{Ib} B H L H$ genes upon iron deficiency. The subgroup Ib $B H L H$ gene expression patterns in the different FIT genotypes were clearly distinct from those of FRO2 and IRTI.

Analysis of subgroup $\mathrm{Ib} B H L H$ promoter-driven GUS activity

We constructed transgenic plants containing subgroup $\mathrm{Ib}$ $B H L H$ promoter-GUS fusions to localize promoter activity at the tissue level and to predict in which cells the subgroup Ib BHLH genes might be active. The BHLHO38, BHLHO39 and $B H L H 100$ promoter-GUS lines revealed GUS staining in roots and leaves which increased in intensity upon low iron supply, in agreement with the qRT-PCR data (Fig. 7). Histochemical GUS staining patterns were confirmed by fluorimetric GUS enzyme activity tests using protein extracts (Fig. 8). GUS activities in root and leaf extracts of transgenic plants containing the pBHLHO38, pBHLHO39 and $p B H L H 100$ promoter-GUS fusions were higher in plants grown upon iron deficiency compared to those exposed to iron supply. pBHLH101-GUS staining was only visible very weakly in iron-deficient leaves but not in roots so that it was not further analysed.

pBHLH038-driven GUS activity was observed in the main root and lateral roots, in particular at the lateral root emergence site (Fig. 7a-f). No GUS activity was apparent in the root tip (Fig. 7b, c, e, f). GUS activity was found in the epidermis of the root hair zone as well as in the epidermis and inside the root of the upper root zone (Fig. 7g, h). In leaves GUS activity was detectable in veins and in 


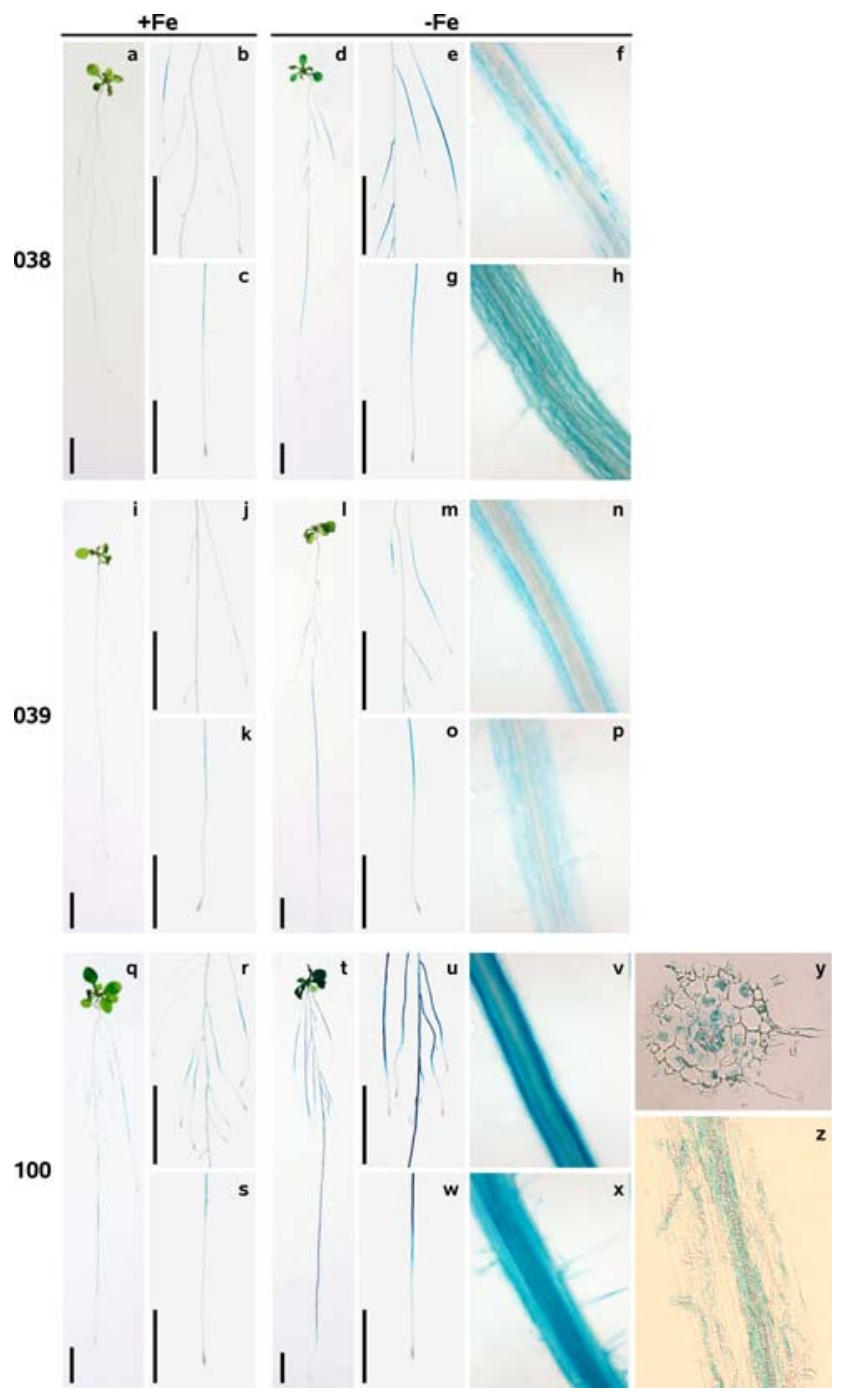

Fig. 7 a-z Histochemical analysis of promoter-driven GUS activity, pBHLH038-GUS (a-h), pBHLH039-GUS (i-p), pBHLH100-GUS $(\mathbf{q}-\mathbf{z})$. Shown are whole seedlings $(\mathbf{a}, \mathbf{d}, \mathbf{i}, \mathbf{l}, \mathbf{q}, \mathbf{t})$, a broad view of the root system (b, e, j, $\mathbf{m}, \mathbf{r}, \mathbf{u})$, a close view of the main root tip $(\mathbf{c}, \mathbf{f}, \mathbf{k}$, $\mathbf{n}, \mathbf{s}, \mathbf{v})$, a microscopic view of the upper root zone $(\mathbf{g}, \mathbf{o}, \mathbf{w})$ and of the root hair zone $(\mathbf{h}, \mathbf{p}, \mathbf{x}), 10 \mu \mathrm{m}$ longitudinal and cross section through the root hair zone $(\mathbf{y}, \mathbf{z})$. Plants were grown for 5 days without iron $(-\mathrm{Fe}, 0 \mu \mathrm{M}$ Fe plus $50 \mu \mathrm{M}$ ferrozine) or with iron supply $(+\mathrm{Fe}, 50 \mu \mathrm{M}$ $\mathrm{Fe}$ ) as indicated. Bars $=0.5 \mathrm{~cm}$

patches in between the veins (not shown). pBHLH039driven GUS activity patterns were as those of $p B H L H 038$ (Fig. 7i-p). pBHLH100-GUS activity was strongest among the four GUS lines. GUS activity was detectable in the epidermis and inside the root except near the root tips (Fig. 7q-x). In leaves, GUS activity was observable in veins and in patches in between the veins especially towards the edges of leaves (not shown). Longitudinal and cross sections revealed that GUS staining occurred in all cells at the root tip (not shown) and that in the root hair zone GUS activity occurred in epidermis, cortex and endo-

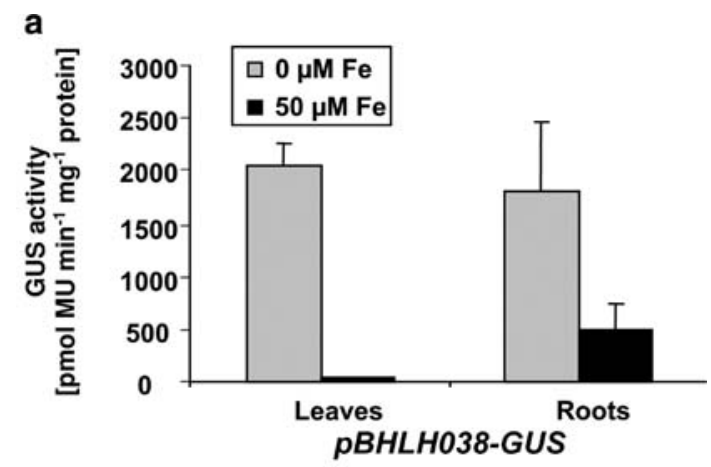

b
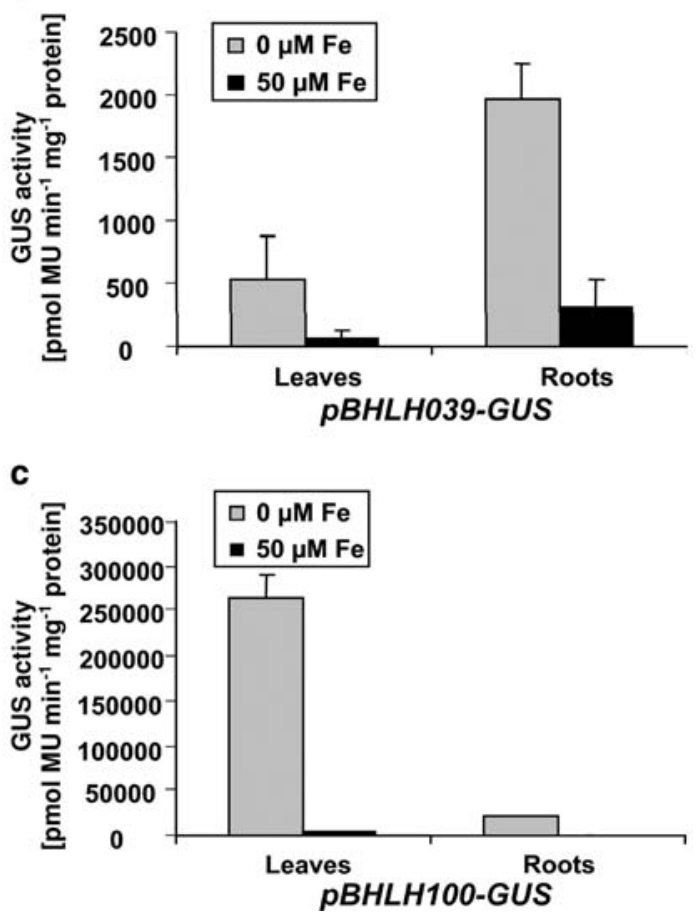

Fig. 8 a-c Fluorimetric analysis of GUS enzyme activity in response to BHLH promoters, pBHLH038-GUS (a), pBHLH039-GUS (b), pBHLH100-GUS (c). Plant protein samples were prepared from roots and leaves of plants grown on $50 \mu \mathrm{M}$ Fe or without iron $(0 \mu \mathrm{M}$ Fe plus $50 \mu \mathrm{M}$ ferrozine). Mean values $\pm \mathrm{SD}$ were determined for four measurements, whereby each measurement included 5-8 plant samples

dermis and was very strong in cells of the vascular cylinder next to the xylem (Fig. 7y, z).

In summary, the GUS activities driven by the subgroup Ib $B H L H$ promoters overlapped with GUS activity patterns observed for $p F I T$ and pIRT1 (see also Vert et al. 2002; Jakoby et al. 2004). pFIT-GUS staining seemed to occur closer to the tip relative to staining patterns of the four $B H L H$ promoters tested.

Split-root assays with $p B H L H 100$ and $p F I T$-GUS lines

The above studies suggested that the four subgroup $\mathrm{Ib}$ BHLH genes might respond to iron deficiency via a 
separate mechanism than IRT1, FRO2 and FIT. To address the regulation by local iron deficiency and systemic signals we performed split-root experiments with promoter-GUS lines (two repetitions). Due to the redundancy of the four subgroup Ib $B H L H$ genes, we concentrated our further studies on BHLH1OO. BHLH1OO was chosen because its responses to metal supply changes were stronger than those of the other three $B H L H$ genes in our studies. Split root halves were exposed for 5 days to $0 \mathrm{Fe}(+50 \mu \mathrm{M}$ ferrozine) and $100 \mu \mathrm{M} \mathrm{Fe}$, respectively. As a control, both split root halves were exposed to either $0 \mathrm{Fe}(+50 \mu \mathrm{M}$ ferrozine) or $100 \mu \mathrm{M} \mathrm{Fe}$, respectively. We found that $p F I T$-driven GUS activity was highest in $0 \mathrm{Fe}$ control roots, and lowest in $100 \mu \mathrm{M}$ control roots. Split roots showed GUS levels that were on both sides in between the levels of control roots. This result indicated that the FIT promoter responded to systemic iron signals (down-regulation on the $0 \mathrm{Fe}$ side and up-regulation on the $100 \mu \mathrm{M}$ Fe side, Fig. 9c).
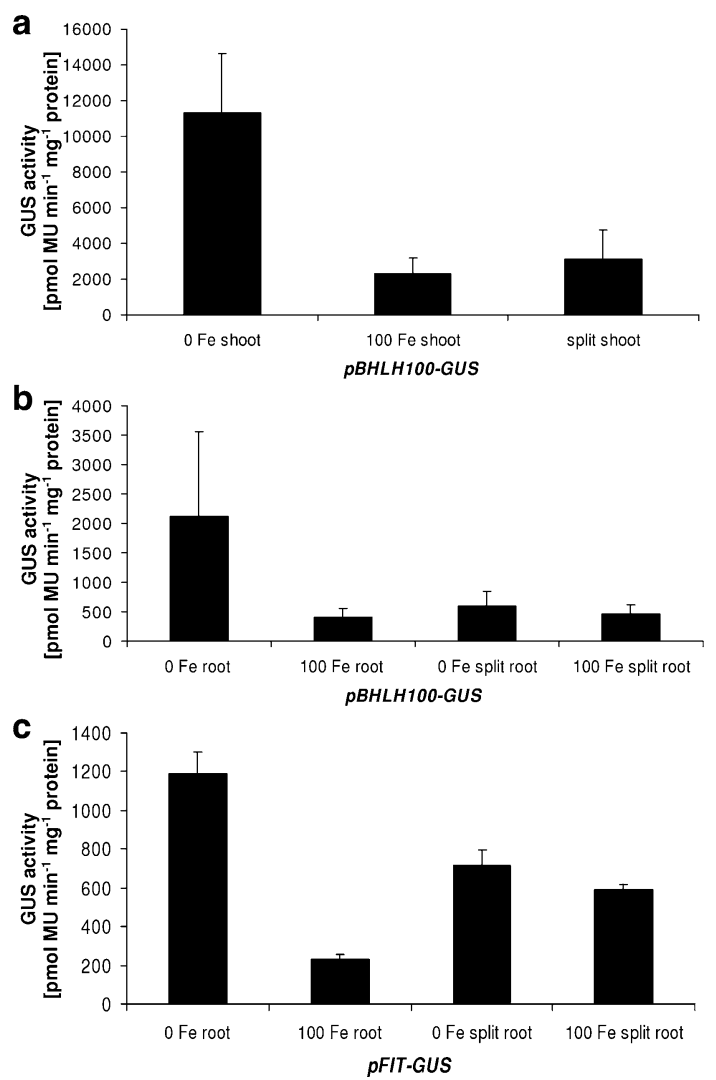

Fig. 9 a-c Fluorimetric analysis of GUS enzyme activity in split-root experiments in plants containing $p B H L H 100_{-} G U S$ (a), pBHLH1OOGUS (b) and pFIT-GUS (c) promoter-GUS constructs. Plant protein samples were prepared from shoots $(\mathbf{a})$ or roots $(\mathbf{b}, \mathbf{c})$ of plants grown for 5 days with split roots. Split roots were exposed to either $0 \mathrm{Fe}$ on both root sides (0 Fe control), or to $100 \mu \mathrm{M} \mathrm{Fe}$ on both sides (100 Fe control), or $0 \mathrm{Fe}$ on one root side and $100 \mu \mathrm{M} \mathrm{Fe}$ on the other root side ( $0 \mathrm{Fe}$ split root and $100 \mathrm{Fe}$ split root, respectively). $0 \mathrm{Fe}$ means $0 \mu \mathrm{M}$ Fe plus $50 \mu \mathrm{M}$ ferrozine. Mean values $\pm \mathrm{SD}$ were determined for three to eight measurements
Interestingly, we found that $p B H L H 100$-driven GUS activity was only induced in $0 \mathrm{Fe}$ control roots. However, in all split-root conditions as well as in the $100 \mu \mathrm{M} \mathrm{Fe}$ control roots GUS levels remained low (Fig. 9b). Expression analysis of the endogenous BHLH1OO gene confirmed the GUS patterns in split-roots (data not shown). The same was found in shoots. GUS levels were much higher in $0 \mathrm{Fe}$ shoots than in $0 \mathrm{Fe}$ roots. However, in shoots of split-root plants the GUS levels remained as low as in $100 \mu \mathrm{M} \mathrm{Fe}$ control shoots (Fig. 9a). Hence, in contrast to FIT we could observe that BHLH1OO was regulated by a different systemic signal than FIT (down-regulation on the $0 \mathrm{Fe}$ side and no up-regulation on the $100 \mu \mathrm{M} \mathrm{Fe}$ side). This observation suggested that BHLH1OO may require for its induction an iron deficiency-induced internal stress signal.

\section{Discussion}

Here we characterized regulation of four iron-regulated transcription factor genes belonging to the large family of more than 160 basic helix-loop-helix genes (Heim et al. 2003; Toledo-Ortiz et al. 2003). Our results indicated strongly that the four subgroup Ib $B H L H$ genes had redundant functions in the plant: Not only were the sequences of the subgroup Ib $B H L H$ genes similar but also their regulation at gene expression level was similar. Finally, single exon insertion mutants had no detectable phenotype. One of our main aims was to analyze whether these four subgroup $\mathrm{Ib} B H L H$ genes might be involved in a regulatory network controlling the essential iron acquisition regulator gene FIT that also belongs to the $B H L H$ gene family (Colangelo and Guerinot 2004; Jakoby et al. 2004). Our second question regarded the potential function of these four genes.

Our work showed that the subgroup Ib $B H L H$ genes were not functionally redundant with the $B H L H$ gene FIT. $F I T$ was not essential for up-regulation of subgroup $\mathrm{Ib}$ $B H L H$ gene expression upon iron deficiency since subgroup $\mathrm{Ib} B H L H$ genes were up regulated in the fit-3 loss of function mutants. Hence, subgroup $\mathrm{Ib} B H L H$ gene induction was not sufficient to compensate the loss of FIT function in terms of promoting iron mobilization. Split-root analyses showed that expression of the FIT promoter could also occur in conditions where the BHLH1OO gene was not expressed (namely either $+\mathrm{Fe}$ or $-\mathrm{Fe}$ side in the split root situations). Therefore, BHLH1OO was not required to induce FIT expression, and FIT and BHLHIOO were differentially regulated by systemic signals. Altogether, we could demonstrate that induction of the four $B H L H$ genes by iron deficiency occurred via a separate pathway than that of FIT in the plants. This conclusion was backed up by a comparison of the promoter activity patterns. IRTI and $F R O 2$ were mainly expressed in the root in the epidermis near the root 
tip and in the upper root zones, induced by low iron and down-regulated in fit loss of function mutants (Eide et al. 1996; Robinson et al. 1999; Vert et al. 2002; Connolly et al. 2003; Colangelo and Guerinot 2004; Jakoby et al. 2004). FIT was also mainly expressed in roots near the root tip and in the upper root zones, induced by low iron and its promoter was down regulated in fit loss of function mutants (Colangelo and Guerinot 2004; Jakoby et al. 2004; this work). In contrast to that, BHLHO38, BHLHO39 and BHLH100 were expressed in roots in the root hair and mature root zones and in leaves, where they were induced upon iron deficiency. Therefore, expression patterns of the subgroup $\mathrm{Ib} B H L H$ genes overlapped partially with the expression patterns of FIT, IRT1 and FRO2 within the root regions where iron mobilization was most relevant. However, from the patterns it seems likely that subgroup $\mathrm{Ib}$ $B H L H$ genes have different functions from FIT.

In FIT overexpression lines that were exposed to iron deficiency (a condition that activated the overexpressed FIT gene product), the four subgroup $\mathrm{Ib} B H L H$ genes were also up regulated. Therefore, we could rule out that FIT was a repressor for the four $B H L H$ genes. Upon iron supply $B H L H$ genes were expressed at lower level in overexpression plants compared to wild type. We know from previous studies that FIT overexpression plants were more tolerant to iron deficiency (Jakoby et al. 2004). Perhaps FIT overexpression plants had better internal iron utilisation capacities, which might have resulted in lower $B H L H$ gene expression. Interestingly, we found these assumptions backed up by gene expression studies using various metal supply conditions. It was not surprising to observe that high zinc and nickel caused subgroup $\mathrm{Ib} B H L H$ gene induction since high zinc and nickel supply can cause iron deficiency. On the other hand, high iron might have caused low zinc and copper nutrition or alternatively low zinc and copper led to better iron mobilization. In these cases subgroup Ib BHLH genes were decreased. Perhaps improved iron mobilization was reflected by decreased subgroup $\mathrm{Ib} B H L H$ gene expression.

Taken together, we exclude that BHLHO38, BHLHO39, BHLH1OO and BHLH1O1 alone regulated any iron mobilization responses in the epidermis near the root tip. It is unlikely that the four subgroup $\mathrm{Ib} B H L H$ genes were regulated downstream of FIT. Rather we think that the four subgroup Ib $B H L H$ genes play a role in controlling events of iron mobilization that occur upstream or in parallel of FIT or in controlling iron deficiency-related aspects that are a consequence of low iron nutrition. We suggest two possible scenarios which might explain regulation of subgroup $\mathrm{Ib}$ $B H L H$ gene expression. First, leaf chlorosis is not only observed as a sign of iron deficiency, but is also a sign for other nutritional imbalances, heavy metal stress, pathogen infection, continued drought. Such leaf stress symptoms might result in enhanced gene expression of $\mathrm{BHLHO38}$, BHLH039, BHLH1OO and BHLH101. Kang et al. (2003) found that $B H L H O 38$ and $B H L H O 39$ were responsive to salicylic acid and required for their expression a salicylic acidinducible transcription factor. Hence, BHLHO38, BHLHO39, BHLH1OO and BHLH1O1 might respond to a systemic stress signal, most likely transmitted through the vascular system. This could explain expression of the four subgroup Ib $B H L H$ genes near the leaf vasculature. Moreover, this could explain that subgroup $\mathrm{Ib} B H L H$ genes were most highly expressed in situations with severe chlorosis due to iron deficiency and most weakly in situations with best iron utilization.

Secondly, the four subgroup $\mathrm{Ib} B H L H$ genes might also be involved in regulating additional aspects of iron mobilization, different from iron uptake into the root. For example, the expression patterns would also be supportive of a function in regulating iron homeostasis in the epidermis and in proximity of the vascular bundles. Such functions could involve import or export of iron from the vascular system. In this respect it is noteworthy that a number of genes involved in aspects of iron transport were found expressed near the vasculature suggesting that these tissues are indeed involved in iron homeostasis (for example Bereczky et al. 2003; Green and Rogers 2004; Jakoby et al. 2004; Jean et al. 2005).

Based on split-root analysis we favour the first hypothesis. BHLH1OO (taken as an example as it was the most strongly responsive subgroup $\mathrm{Ib} B H L H$ gene) was not induced in split roots exposed to iron deficiency. At the same time FIT was activated in this situation. Perhaps a systemic signal as negative regulator was produced for suppression of BHLH1OO in the split-root situation, which signalled that iron deficiency did not occur (since there was a $+\mathrm{Fe}$ root side where iron was taken up) despite of no iron availability near the root. Or a positive systemic signal was absent that usually signals to the root and shoot that iron deficiency occurred and which normally in non-split root situations leads to up-regulation of $B H L H 100$. The expression in split-roots was clearly differing between $\mathrm{BHLH} 100$ and FIT. FIT was induced in the split-root situation at similar level on the iron supply side as well as on the iron deficiency side. This level was intermediate between the two control situations. Hence, we conclude that FIT was controlled by a different systemic signal than BHLH100. FIT might have been induced on the iron supply side in response to a systemic signal produced after sensing local iron deficiency on the iron deficiency side, as was previously described for IRTI (Vert et al. 2003). Hence, FIT and IRT1 were expressed to achieve iron mobilization in the root parts where iron was most available, whereas up-regulation of BHLH1OO presumably only occurred in response to stress. From studies of various chlorotic mutants and 
metal supply conditions we could further conclude that subgroup Ib $B H L H$ genes were not induced by a general stress in the plant but that iron deficiency-induced stress seemed required. For example, iron deficiency situations (like $-\mathrm{Fe}$, high zinc, nickel) induced gene expression as well as typical iron mobilization mutant backgrounds (irtl, frdl, fit, manl) whereas on the other hand non-iron deficiencyinduced leaf stress like observed upon high iron supply $(500 \mu \mathrm{M} \mathrm{Fe})$ was neutral with respect to subgroup Ib $B H L H$ induction. Interestingly, the recent work of two other groups also suggested that $B H L H 1 O O$ was induced by high zinc (as discovered by gene chip experiments), whereas it was repressed by low zinc (Talke et al. 2006; van de Mortel et al. 2006).

Hence, our overall conclusion is that subgroup $\mathrm{Ib} B H L H$ genes may play a role in the alleviation of iron deficiencyinduced stress symptoms in the plant. In the future it will be very interesting to undertake the lengthy approach to knock out subgroup $\mathrm{Ib} B H L H$ functions to further prove this hypothesis and utilise knockout tool to define classes of target genes.

Acknowledgments This work was supported by an Emmy Noether grant from the Deutsche Forschungsgemeinschaft to PB and by EEC grants in the REGIA program to HB and BW. We thank Dr. C. Curie (Montpellier) for irt1-1 seeds.

\section{References}

Bauer P, Thiel T, Klatte M, Bereczky Z, Brumbarova T, Hell R, Grosse I (2004) Analysis of sequence, map position, and gene expression reveals conserved essential genes for iron uptake in Arabidopsis and tomato. Plant Physiol 136:4169-4183

Bereczky Z, Wang HY, Schubert V, Ganal M, Bauer P (2003) Differential regulation of nramp and irt metal transporter genes in wild type and iron uptake mutants of tomato. J Biol Chem 278:2469724704

Clough SJ, Bent AF (1998) Floral dip: a simplified method for Agrobacterium-mediated transformation of Arabidopsis thaliana. Plant J 16:735-743

Colangelo EP, Guerinot ML (2004) The essential basic helix-loop-helix protein FIT1 is required for the iron deficiency response. Plant Cell 16:3400-3412

Connolly EL, Campbell NH, Grotz N, Prichard CL, Guerinot ML (2003) Overexpression of the FRO2 ferric chelate reductase confers tolerance to growth on low iron and uncovers posttranscriptional control. Plant Physiol 133:1102-1110

de Folter S, Busscher J, Colombo L, Losa A, Angenent GC (2004) Transcript profiling of transcription factor genes during silique development in Arabidopsis. Plant Mol Biol 56:351-366

Duek PD, Fankhauser C (2005) bHLH class transcription factors take centre stage in phytochrome signalling. Trends Plant Sci 10:51-54

Eide D, Broderius M, Fett J, Guerinot ML (1996) A novel iron-regulated metal transporter from plants identified by functional expression in yeast. Proc Natl Acad Sci USA 93:5624-5628

Green LS, Rogers EE (2004) FRD3 controls iron localization in Arabidopsis. Plant Physiol 136:2523-2531
Heim MA, Jakoby M, Werber M, Martin C, Weisshaar B, Bailey PC (2003) The basic helix-loop-helix transcription factor family in plants: a genome-wide study of protein structure and functional diversity. Mol Biol Evol 20:735-747

Jakoby M, Wang HY, Reidt W, Weisshaar B, Bauer P (2004) FRU (BHLHO29) is required for induction of iron mobilization genes in Arabidopsis thaliana. FEBS Lett 577:528-534

Jean ML, Schikora A, Mari S, Briat JF, Curie C (2005) A loss-of-function mutation in AtYSL1 reveals its role in iron and nicotianamine seed loading. Plant J 44:769-782

Jefferson RA, Kavanagh TA, Bevan MW (1987) GUS fusions: betaglucuronidase as a sensitive and versatile gene fusion marker in higher plants. EMBO J 6:3901-3907

Kang HG, Foley RC, Onate-Sanchez L, Lin C, Singh KB (2003) Target genes for OBP3, a Dof transcription factor, include novel basic helix-loop-helix domain proteins inducible by salicylic acid. Plant J 35:362-372

Li L, Cheng X, Ling HQ (2004) Isolation and characterization of $\mathrm{Fe}(\mathrm{III})$-chelate reductase gene LeFRO1 in tomato. Plant Mol Biol 54:125-136

Ling HQ, Bauer P, Bereczky Z, Keller B, Ganal M (2002) The tomato fer gene encoding a bHLH protein controls iron-uptake responses in roots. Proc Natl Acad Sci USA 99:13938-13943

Robinson NJ, Procter CM, Connolly EL, Guerinot ML (1999) A ferricchelate reductase for iron uptake from soils. Nature 397:694-697

Rogers EE, Guerinot ML (2002) frd3, a member of the multidrug and toxin efflux family, controls iron deficiency responses in Arabidopsis. Plant Cell 14:1787-1799

Römheld V (1987) Different strategies for iron acquisition in higher plant. Physiol Plant 70:231-234

Rozen S, Skaletsky H (2000) Primer3 on the WWW for general users and for biologist programmers. In: Krawetz S, Misener S (eds) Bioinformatics methods and protocols: methods in molecular biology. Humana Press, Totowa, pp 365-386

Schiefelbein J (2003) Cell-fate specification in the epidermis: a common patterning mechanism in the root and shoot. Curr Opin Plant Biol 6:74-78

Talke IN, Hanikenne M, Kramer U (2006) Zinc-dependent global transcriptional control, transcriptional deregulation, and higher gene copy number for genes in metal homeostasis of the hyperaccumulator Arabidopsis halleri. Plant Physiol 142:148-167

Toledo-Ortiz G, Huq E, Quail PH (2003) The Arabidopsis basic/helixloop-helix transcription factor family. Plant Cell 15:1749-1770

van de Mortel JE, Villanueva LA, Schat H, Kwekkeboom J, Coughlan S, Moerland PD, van Themaat EvL, Koornneef M, Aarts MGM (2006) Large expression differences in genes for iron and zinc homeostasis, stress response, and lignin biosynthesis distinguish roots of Arabidopsis thaliana and the related metal hyperaccumulator Thlaspi caerulescens. Plant Physiol 142:1127-1147

Vert G, Grotz N, Dedaldechamp F, Gaymard F, Guerinot ML, Briat JF, Curie C (2002) IRT1, an Arabidopsis transporter essential for iron uptake from the soil and for plant growth. Plant Cell 14:12231233

Vert GA, Briat JF, Curie C (2003) Dual regulation of the Arabidopsis high-affinity root iron uptake system by local and long-distance signals. Plant Physiol 132:796-804

Vorwieger A, Gryczka C, Czihal A, Douchkov D, Tiedemann J, Mock HP, Jakoby M, Weisshaar B, Saalbach I, Baumlein H (2007) Iron assimilation and transcription factor controlled synthesis of riboflavin in plants. Planta (in press)

Yuan YX, Zhang J, Wang DW, Ling HQ (2005) AtbHLH29 of Arabidopsis thaliana is a functional ortholog of tomato FER involved in controlling iron acquisition in strategy I plants. Cell Res 15:613621 